\title{
Embolization with Gamma Knife Radiosurgery of Giant Intracranial Arteriovenous Malformations
}

\author{
Dong Hyun CHUN¹, Moo Seong KIM¹, Sung Tae KIM¹, Sung Hwa PAENG ${ }^{1}$, Hae Woong JEONG², Won Hee LEE \\ ${ }^{1}$ Inje University, School of Medicine, Busan Paik Hospital, Department of Neurosurgery, Busan, Korea \\ ${ }^{2}$ Inje University, School of Medicine, Busan Paik Hospital, Department of Diagnostic Radiology, Busan, Korea
}

\section{ABSTRACT}

AIM: Giant arteriovenous malformations (i.e., those greater than $6 \mathrm{~cm}$ maximum diameter or volume $>33 \mathrm{cc}$ ) are difficult to treat and often carry higher treatment morbidity and mortality rates. In our study, we reviewed the angiographic results and clinical outcomes for 11 patients with giant arteriovenous malformations who were treated between 1994 and 2012.

MATERIAL and METHODS: The patients selected included 9 males (82\%) and 2 females (18\%). Their presenting symptoms were hemorrhage $(n=2 ; 18 \%)$, seizure $(n=7 ; 64 \%)$, and headache $(n=2 ; 12 \%)$. Nine patients were Spetzler-Martin Grade III, 2 were Spetzler-Martin Grade IV. The mean arteriovenous malformation volume was $41 \mathrm{cc}(33-52 \mathrm{cc})$. The mean age of the patients was 45.1 years (24-57 years) and the mean radiation dose delivered to the margin of the nidus was 14.2 Gy.

RESULTS: Ten patients received pre-Gamma Knife radiosurgery embolization and Gamma Knife radiosurgery, 1 patient received pre-Gamma Knife radiosurgery embolization and Gamma Knife radiosurgery twice and the interval between Gamma Knife radiosurgeries was 3 months. The complete obliteration rate following Gamma Knife radiosurgery was 36\%, subtotal obliteration (> $70 \%$ decreased size of nidus) was $36 \%$, and partial obliteration was $28 \%$. One patient experienced a small hemorrhage after embolization.

CONCLUSION: Combined embolization and Gamma Knife radiosurgery showed successful obliteration of the arteriovenous malformation nidus. The use of embolization to initially reduce nidus size followed by Gamma Knife radiosurgery improves the treatment results. Repeated Gamma Knife radiosurgery should be a treatment option when there is a small nidus remnant.

KEYWORDS: Embolization, Giant arteriovenous malformations, Gamma Knife radiosurgery

\section{INTRODUCTION}

$\mathrm{S}$ tereotactic radiosurgery is a valuable therapeutic modality in the management of arteriovenous malformations (AVMs) (20). However, giant AVMs have higher treatment morbidity and mortality rates than smaller AVMs (4, 9). An accepted definition of giant AVM is angiographically measured vascular malformations greater than $6 \mathrm{~cm}$ in maximum diameter (4). Due to the giant size of the AVM, it means they are invariably high-flow, and are placed within or immediately adjacent to lesions which often have deep venous drainage (4). The development of embolization materials such as Onyx (ev3, Inc., Irvine, CA) have been increasing obliteration rate of AVMs after embolization $(25,26)$. Pre-radiosurgery embolization allows better dose planning by decreasing the size of AVMs $(25,26)$. In our study, we assessed angiographic results and clinical outcomes in 11 giant AVM patients treated with Gamma Knife radiosurgery (GKS) and embolization between 1994 and 2012.

\section{MATERIAL and METHODS}

\section{Patients}

Between 1994 and 2012, 11 patients underwent GKS and embolization for giant brain AVMs at Inje University Busan 
Paik Hospital in Korea. There were 9 (82\%) male and 2 (18\%) female patients, and the age range was 24 to 57 years (mean, 45.1 years). Seven patients (64\%) presented with seizure, two patients (18\%) developed cerebral hemorrhage before radiosurgery, and the rest of the patients (18\%) complained of headache.

Initial surgery grade of the AVMs, based on the SpetzlerMartin scale, was Grade III in nine patients, and Grade IV in two patients. The mean pretreatment volume of the AVMs was $41 \mathrm{cc}$ (range, 33-52 cc). The mean dose to the AVM margin was 14.2 Gy. Calculation of the volume of the AVM and the integrated logistic formula was used to determine the prescription dose to achieve a permanent brain injury risk less than $3 \%$.

The institutional review board of Inje University Busan Paik Hospital approved this study (14-0248).

\section{Follow-up Evaluation}

Post-GKS magnetic resonance angiographies (MRA) or computed tomography angiographies (CTA) were obtained annually. The MRA or CTA obtained at 3-5 years revealed regression of flow. Angiography was performed and analyzed following complete obliteration, subtotal obliteration (>70\% decreased the size of nidus), or partial obliteration.

Overall, the patients underwent 1 embolization-GKS session, and 1 session consisted of 1 pre-GKS embolization followed by $1 \mathrm{GKS}$. One patient had 1 pre-GKS embolization followed by GKS twice at a 3-month interval. The GKS was performed 2 weeks after embolization on average.

\section{RESULTS}

Four patients (36\%) were angiographically obliterated of their giant AVMs (Figures 1A-C, 2A-D). Four patients (36\%) had subtotal obliteration, and 3 patients (28\%) exhibited partial obliteration. One patient experienced a small amount of cerebral hemorrhage after embolization and she received GKS
2 weeks later when the cerebral hemorrhage was resolved. The mean follow-up period was 44.7 months (range, 12-108 months). There was no patient who suffered from radiationinduced complications.

\section{DISCUSSION}

Cerebral AVMs are often associated with a significant risk of morbidity and mortality due to intracerebral hemorrhage, seizure or neurologic deficits secondary to venous hypertension or vascular steal. Intervention may be indicated to eliminate the risk of hemorrhage and to preserve or improve neurologic function (26).

Treatment strategies for giant cerebral AVMs have evolved significantly. Microsurgery, radiosurgery, and embolization have been successfully used either alone or in combination (21). Although the response may differ according to embolic agents, endovascular therapy results in an inflammatory process and fibrosis that may lead to vessel occlusion. When the nidus is incompletely embolized, collateral vessels can form leading to recanalization (5).

Key determinants of complications following embolization reported in the literature are the number of embolization procedures, the number of embolized arterial feeders, eloquent location, location in the basal ganglia, deep venous drainage, size $<3 \mathrm{~cm}$, size $>6 \mathrm{~cm}$, Spetzler-Martin grade III to $\mathrm{V}$, venous penetration of glue cast, and AVMs with a pure fistula or a nidus with a fistulous component $(28,29)$.

Pre-radiosurgery embolization allows the better dose planning by decreasing the size of AVMs. Additional treatment goals may include staged reduction of blood flow in an AVM by stepwise occlusion of deep feeding arteries that could provide dose planning to more critical locations $(14,17-19,22)$.

In the study by Blackburn et al. (3), 21 AVMs with a diameter $>3 \mathrm{~cm}$ were treated with embolization and radiosurgery, including 12 (57\%) Spetzler-Martin grade IV or V lesions. Forty-three embolization procedures were performed;
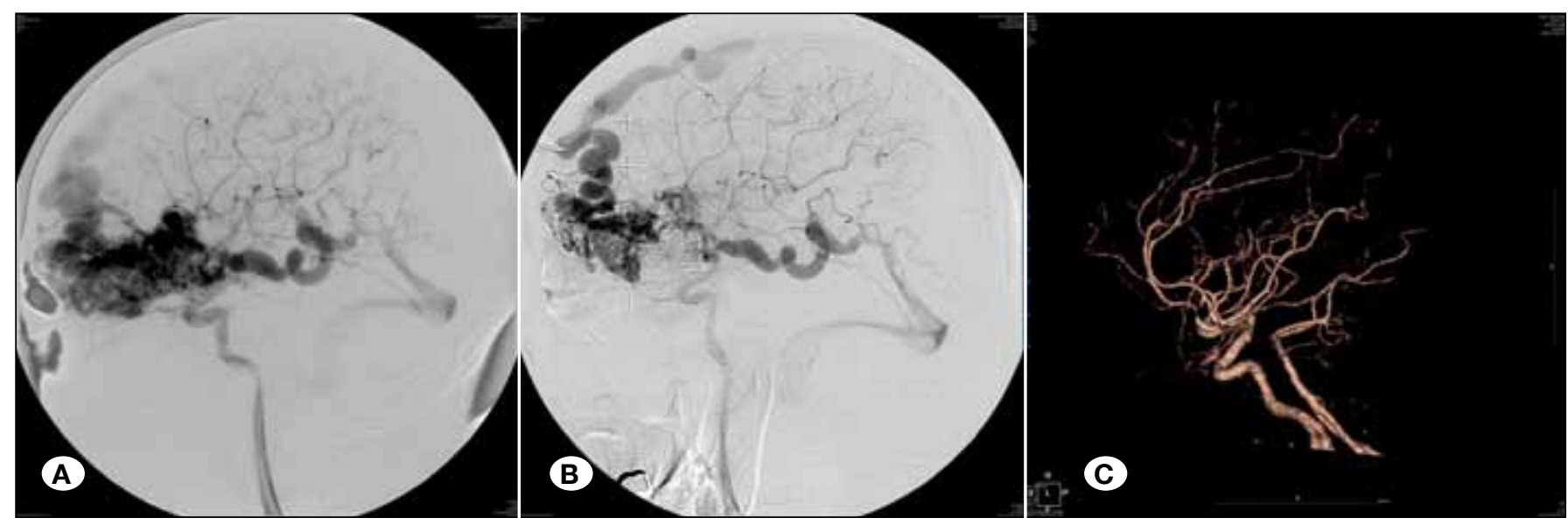

Figure 1: A 48-year-old male patient with seizure received pre-GKS embolization followed by GKS twice at 3 months interval with marginal dose 10 Gy. CT angiography after 4 years of treatment showed complete obliteration of AVM nidus. (A: Pre-embolization angiography, B: Post-embolization angiography, C: Follow-up CT angiography). 


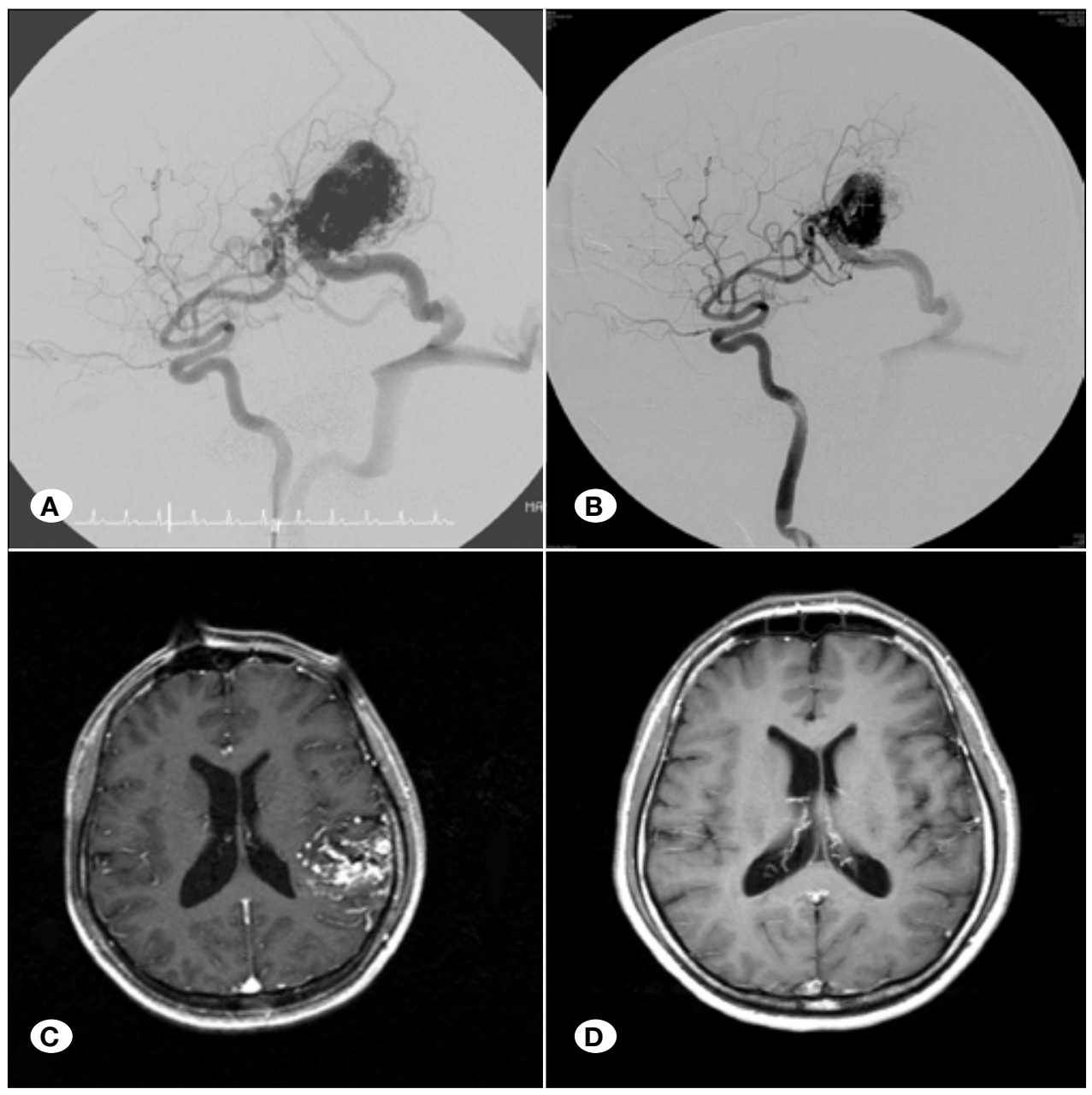

Figure 2: A 42-year-old female patient presented with seizure and she received pre-GKS embolization followed by GKS with marginal dose 12 Gy. 9 years later, follow-up MRI showed nearly total obliteration of AVM nidus.

(A: Pre-embolization angiography, B: Post-embolization angiography, C: MRI for GKS, D: Follow-up MRI).

8 embolization-related complications occurred, of which 5 were transient neurological deficit and 3 were minor permanent neurological deficit. In a study by Andrade Souza et al. (1), 47 patients with a history of radiosurgery and embolization were matched according to volume, location, and marginal dose to 47 patients with radiosurgery and no history of embolization. Nidus obliteration was achieved in $47 \%$ of patients with a history of embolization and $70 \%$ of patients without a history of embolization. Permanent deficits related to hemorrhage or radiation occurred in $6 \%$ of both groups. At the University of Virginia, 1,012 patients have received planned single-session GKS with a minimum of two years follow-up. In Spetzler-Martin grade III or IV AVMs, $27 \%$ were treated with embolization prior to radiosurgery. Spetzler-Martin grade III or IV lesions have significantly lower rates of obliterations (64\%) as compared to grade I and II lesions (74\%). Transient symptomatic radiationinduced complications were significantly higher in larger lesions (11.6\%) versus smaller lesions (8.5\%) (23).

Anson and Spetzler (2) reported 32 giant AVM patients who were in Spetzler-Martin Grade V. Of these, 15 patients showed clinical improvement, 7 patients did not changed clinical status. 10 patients were aggravated deficits, albeit 8 of these patients were either mild or transient deficit. Three of the four patients who needed surgical resection also required presurgical embolization to decrease the size of AVM.

Heros et al. (16) described giant AVMs among the series of AVM that enrolled 153 patients. For the entire AVM series, Heros et al. reported that $61 \%$ of Grade IV and $29 \%$ of Grade $\mathrm{V}$ patients were achieved early good or excellent outcomes. Patients improved with morbidity and mortality rates were only $12 \%$ of their Grade IV and $38 \%$ of Grade V of their AVMs with longer follow-up.

Hernesniemi and Keranen (15) described that 15 patients had AVMs larger than $5 \mathrm{~cm}$ out of 90 patients with AVMs. Among them, excellent outcome was reported in 5 patients, moderate disability in 6 patients, severe disability and death in one patient each, while 2 patients were lost to follow-up. A great number of giant AVMs have deep components within the thalamus and the basal ganglia, and annual hemorrhage rates have been shown to be as high as $9.6 \%$ in recent studies among individuals within this subgroup of AVMs (23). The risk of treatment may prevail the risk of natural history in the lesions, so observation alone is the best treatment for a small subgroup of patients with giant AVMs, including those who are elderly or medically infirm (4). 
Chang et al. (4) studied 53 patients with giant AVMs who were treated at Stanford between 1987 and 2001. One patient was Spetzler-Martin Grade III, and 9 patients were SpetzlerMartin Grade V. The mean size of AVM was $6.8 \mathrm{~cm}$ (range, 6-15 cm). Treatment modalities consisted of surgery $(n=27$, $51 \%)$, embolization $(n=52,98 \%)$, and/or radiosurgery $(n=47$, $89 \%$ ). Most patients underwent multimodal treatment. 51 patients were treated with embolization followed by surgery, 23 patients received embolization followed by radiosurgery and 23 patients underwent multimodal treatment that was composed with embolization, radiosurgery, and surgery. AVMs were cured in 19 patients (58\%) out of the 33 patients. These patients completed treatment or survived more than 3 years following their latest radiosurgery. The long-term morbidity rate related to treatment was $15 \%$. The clinical outcome showed that the status of 27 patients was excellent (51\%), 15 patients were good (28\%), 3 patients were poor $(6 \%)$, and 8 patients were dead (15\%) after the mean follow-up period (37 months). Multimodal treatment consisting of embolization, microsurgery and radiosurgery may result in optimal outcome (4). Dalyai et al. (6) reported on ninety-five patients with larger AVMs who were treated with staged endovascular embolization followed by stereotactic radiosurgery (SRS) between 1996 and 2011. The median volume of AVM in this group was $28 \mathrm{~cm}^{3}$ and 47 patients (48\%) were Spetzler-Martin grade IV or V. Sixty-one patients underwent multiple embolizations while a single SRS session was performed in 64 patients. The median followup after SRS session was 32 months (range 9-136 months). Overall procedural complications occurred in 14 patients. There were 13 minor neurological complications and 1 major complication (due to embolization) while four patients had post-treatment hemorrhage. Thirty-eight patients (40\%) were cured radiographically. The post-radiosurgery actuarial rate of obliteration was $45 \%$ at 5 years, $56 \%$ at 7 years, and $63 \%$ at 10 year. In multivariate analysis, larger AVM size, deep venous drainage, and the increasing number of embolization/SRS sessions were negative predictors of obliteration. The number of embolization was correlated positively with the number of stereotactic radiosurgeries. A multimodal endovascular and radiosurgical approach is an efficacious treatment strategy for large AVMs. In our 11-patient study group, ten patients received 1embolization-GKS session, 1 patient received preGKS embolization and GKS twice over 3 months intervals. The complete obliteration rate following GKS was $36 \%$, subtotal obliteration ( $>70 \%$ decrease of nidus) rate was $36 \%$, while the partial obliteration rate was $28 \%$. One patient experienced a small hemorrhage after embolization

Radiosurgery causes proliferation of endothelial cell, progress to vessel wall thickening, and finally closure of the lumen. Inhibition of neovascularization depends on the radiation dose (5). Endovascular treatment results caused by inflammatory process and fibrosis may lead to vessel occlusion. When the nidus is incompletely embolized, collateral vessels are formed and can lead to re-canalization $(11,27)$. Pre-radiosurgery embolization caused the staged reduction of blood flow in the AVM by stepwise occlusion of the AVM nidus and elimination of deep-feeding arteries (7, 8, 12, 13, 30). 'Good' AVMs are suitable for surgical resection, 'Bad' AVMs fit for radiosurgery.
'Good' AVMs are small sized $(<3 \mathrm{~cm})$, with an accessible area, combined with large hematoma. 'Bad' AVMs are in the sensory or motor or visual cortex AVM, large size $(\geq 3 \mathrm{~cm})$ in critical locations (thalamus, brainstem), affect the deep venous drainage, or are posterior cerebral artery P3, or P4 segment supplied AVMs. Chang et al. (4) showed that combinations of microsurgery, embolization and SRS were often required to obliterate a giant AVM completely. Embolization reduces the volume of nidus that requires surgical resection but stereotactic radiosurgery several years prior to resection provides beneficial results also. In some patients, volume of required surgical resection was significantly decreased by partial AVM thrombosis. More important, the irradiated AVMs, even in non-embolized area, were found to have a much less prominent vascular component than un-irradiated AVMs at the time of surgery. AVM vessels that were treated radiosurgically were coagulated easier with bipolar electrodes, so that could facilitate the resection and make it quicker and safer with less blood loss (24). Radiosurgery can be considered a preoperative adjunctive treatment to obliterate parts of giant AVMs, thereby reducing the remaining nidus size for surgical resection (24). Staged stereotactic radiosurgery has been recommended by some authors for the treatment of giant AVM patients (10). In these cases, to prevent conducting radiation dose to a single large target for theoretically decreasing the risk of complications related to radiation, radiosurgical treatments are divided into multiple stages at various intervals to different portions of the AVM. Algorithms for treatment of giant AVMs have been illustrated briefly (Figure 3).

\section{CONCLUSION}

The combination of embolization and GKS showed successful obliteration of AVM nidus. The use of embolization to initially

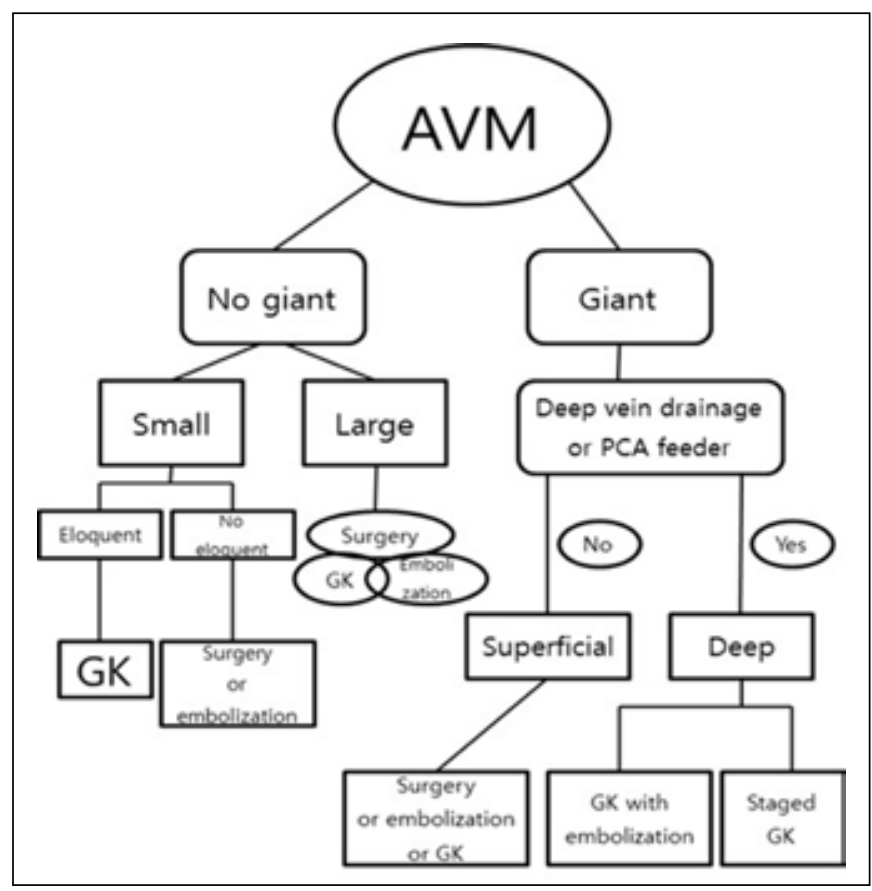

Figure 3: Algorithms for treatment of giant AVM. 
reduce nidus size followed by GKS improves the treatment results of AVMs. Repeated GKS should be a treatment option when there is only a small remnant of the nidus.

\section{ACKNOWLEDGEMENT}

This work was supported by Inje Research and Scholarship Foundation in 2014.

\section{REFERENCES}

1. Andrade-Souza YM, Ramani M, Scora D, Tsao MN, terBrugge $\mathrm{K}$, Schwartz ML: Embolization before radiosurgery reduces the obliteration rate of arteriovenous malformations. Neurosurgery 60:443-451, 2007

2. Anson JA, Spetzler RF: Giant arteriovenous malformations. In: Carter LP, Spetzler RF, Hamilton MG (eds), Neurovascular Surgery. New York: McGraw-Hill, 1995:1017-1028

3. Blackburn SL, Ashley WW, Rich KM, Simpson JR, Drzymala RE, Ray WZ, Moran CJ, Cross III DT, Chicoine MR, Dacey Jr RG: Combined endovascular embolization and stereotactic radiosurgery in the treatment of large arteriovenous malformations: Clinical article. J Neurosurg 114:1758-1767, 2011

4. Chang SD, Marcellus ML, Marks MP, Levy RP, Do HM, Steinberg GK: Multimodality treatment of giant intracranial arteriovenous malformations. Neurosurgery 53(1):1-13, 2003

5. Connors JJ, Wojak JC: Interventional Neuroradiology: Strategies and Practical Techniques. Philadelphia, PA: WB Saunders, 1999

6. Dalyai R, Theofanis T, Starke RM, Chalouhi N, Ghobrial G, Jabbour P, Dumont A, Fernando GL, Gordon DS, Rosenwasser $\mathrm{RH}$ : Stereotactic radiosurgery with neoadjuvant embolization of large arteriovenous malformations: An institutional experience. BioMed Res Int 2014:1-8, 2014

7. Debrun GM, Aletch V, Ausman JI, Charbel F, Dujovny M: Embolization of the nidus of brain arteriovenous malformations with n-butyl cyanoacrylate. Neurosurgery 40:112-120, 1997

8. Deruty R, Pelissou-Buyotat I, Amat D, Mottolese C, Bascoulergue $\mathrm{Y}$, Turjman F, Gerard JP: Complications after multidisciplinary treatment of cerebral arteriovenous malformations. Acta Neurochir (Wien) 138:119-131, 1996

9. Drake CG. Cerebral arteriovenous malformations: Considerations for and experience with surgical treatment in 166 cases. Clin Neurosurg 26:145-208, 1979

10. Firlik AD, Levy El, Kondziolka D, Yonas $H$ : Staged volume radiosurgery followed by microsurgical resection: $A$ novel treatment for giant cerebral arteriovenous malformationsTechnical case report. Neurosurgery 43:1223-1228, 1998

11. Fleetwood IG, Marcellus M, Levy RP, Marks MP, Steinberg GK: Deep arteriovenous malformations of the basal ganglia and thalamus: Natural history. J Neurosurg 98:747-750, 2003

12. Fournier D, terBrugge KG, Willinsky $R$, Lasjaunias $P$, Montanera W: Endovascular treatment of intracerebral arteriovenous malformations; experience in 49 cases. J Neurosurg 75:228233, 1991

13. Frizzel RT, Fisher WS: Cure, morbidity, and mortality associated with embolization of brain arteriovenous malformations: A review of 1246 patients in 32 series over a 35-year period. Neurosurgery 37:1031-1039, 1995

14. Haw CS, terBrugge K, Willinsky R, Tomlinson G: Complications of embolization of arteriovenous malformations of the brain. $J$ Neurosurg 104:226-232, 2006
15. Hernesniemi J, Keranen T: Microsurgical treatment of arteriovenous malformations of the brain in a defined population. Surg Neurol 33:384-390, 1990

16. Heros RC, Korosue K, Diebold PM: Surgical excision of cerebral arteriovenous malformation embolization using liquid embolic agents. AJNR Am J Neuroradiol 29:242-246, 2008

17. Jayaraman MV, Marcellus ML, Hamilton S, Do HM, Campbell D, Chang SD, Steinberg GK: Neurologic complications of arteriovenous malformation embolization using liquid embolic agents. AJNR AM J Neuroradiol 29:242-246, 2008

18. Kim IJ. Albuquerque FC, Spetzler RF, McDougall CG: Postembolization neurological deficits in cerebral arteriovenous malformations: Stratification by arteriovenous malformation grade. Neurosurgery 59:53-59, 2006

19. Ledezma CJ, Hoh BI, Carter BS, Pryor JC, Putman CM, Ogilvy CS: Complications of cerebral arteriovenous malformation embolization: Multivariate analysis of predictive factors. Neurosurgery 58:602-611, 2006

20. Spetzler RF, Martin NA: A proposed grading system for arteriovenous malformations. J Neurosurg 65:476-483, 1986

21. Starke RM, Dumont AS: Radiosurgery of arteriovenous malformations without embolization. In: Jasa P Sheehan Pater Gersztn (ed), Controversies in Stereotactic Radiosurgery. Best Evidence Recommendations. New York: Thieme, 2014: 68-74

22. Starke RM, Komotar RJ, Ottem ML, Merkow MB, Otten ML, Connolly ES: Adjuvant embolization in the treatment of cerebral arteriovenous malformations: Outcomes, complications, and predictors of neurologic deficits. Paper presented at: Congress of Neurological Surgeons, Orlando, FL, 2008

23. Starke RM, Yen CP, Ding D, Sheehan JP: A practical grading scale for predicting outcome after radiosurgery for arteriovenous malformations: Analysis of 1012 treated patients. J Neurosurg 119(4): 981-987, 2013

24. Steinberg GK, Chang SD, Levy RP, Marks MP, Frankel K, Marcellus M: Surgical resection of large incompletely treated intracranial arteriovenous malformations following stereotactic radiosurgery. J Neurosurg 84: 920-928, 1996

25. Steinberg G, Marks MP: Intracranial arteriovenous malformations: Therapeutic options. In: Batjer HH (ed), Cerebrovascular Disease. Philadelphia, PA: Lippincott-Raven, 1997: 727-742

26. Steinberg GK, Marks MP, Levy RP, Fabrikant Jl: Multimodality treatment of vascular malformations in functional brain areas using stereotactic radiosurgery, embolization and microsurgery. In: Yamada S (ed), Arteriovenous Malformations in Functional Areas of the Brain. Armonk, NY: Futura Publishing Co., 1999:181-196

27. Sure U, Butz N, Schlegel J, Siegel AM, Wakat JP, Mennel HD, Bien S, Bertalanffy $\mathrm{H}$ : Endothelial proliferation, neoangiogenesis, and potential de novo generation of cerebrovascular malformations. J Neurosurg 94(6): 972-977, 2001

28. Vinuela F, Fox AJ, Debrun G, Darke CG, Peerless SJ, Girvin JP: Progressive thrombosis of brain arteriovenous malformations after embolization with isobutyl 2-cyanoacrylate. AJNR Am J Neuroradiol 4:1233-1238, 1983

29. Wikholm G, Lundqvist C, Svendsen P: Transarterial embolization of cerebral arteriovenous malformations: Improvement of results with experience. AJNR Am J Neuroradiol 16:18111817, 1995

30. Wikholm G, Lundqvist C, Svendsen P: Embolization of cerebral arteriovenous malformations: Part I-Technique, morphology, and complications. Neurosurgery 39:448-457, 1996 